\title{
Editorial Special Issue "Heterogeneous Catalytic Materials: Synthesis, Characterization and Applications for Energetic Purposes"
}

\author{
Catia Cannilla ${ }^{\mathbb{D}}$ \\ Institute for Advanced Energy Technologies “Nicola Giordano” ITAE, Italian National Research Council (CNR), \\ 98126 Messina, Italy; catia.cannilla@itae.cnr.it
}

Received: 29 September 2020; Accepted: 3 October 2020; Published: 13 October 2020

Solid catalytic materials play a key role in the development of industrial chemistry, showing important advantages over liquid materials thanks to their easier separation from the reaction liquid medium, their reusability and stability, and their environmentally friendly character. This Special Issue is focused on the actual and potential application of heterogeneous catalysts for energetic purposes, as biofuels synthesis and $\mathrm{H}_{2}$ production through biomass, waste, biogas or $\mathrm{CO}_{2}$ conversion and environmental issues, such as $\mathrm{CO}$ and NOx abatements, with specific interest towards innovative procedures of synthesis or catalytic formulations and chemico-physical characterization techniques. For example, in situ and operando characterization techniques represent a suitable tool to identify and quantify the nature and functionality of surface adsorption active sites and, therefore, for correlating the catalytic behaviour with the surface properties of the investigated systems [1]. Specifically, transient measurement techniques have been applied for the kinetic investigation of the reaction mechanism, using diffuse reflectance infrared spectroscopy (DRIFT) and mass spectrometry. The coupled information of the time evolution of surface intermediates and gas phase components, in fact, could lead to accurate identification of spectator species on the surface.

Copper-zirconia catalysts are extremely versatile and tuneable materials, characterized by redox and acid-base properties which could be modulated by modifying the zirconia and copper ratio. Scotti et al. [2] reviewed recent advances in the use and the development of such kinds of catalysts for methanol synthesis and steam reforming and for the dehydrogenative coupling reactions. Main aspects of reaction mechanisms based on copper exposure, the copper-zirconia interphase, the zirconia surface hydroxylation degree and acid base properties are discussed, considering their impact on the surface hydrogen and intermediates mobility and on the electronics and stability of the copper phase. Contrarily to the large number of investigations focusing on the zirconia crystallographic phase, authors indicated the degree of surface hydroxylation and the copper-zirconia interphase as the two mostly determining factors to be controlled to achieve high catalytic performances. Main drawbacks still hampering the implementation of the industrial scale are the fine control over the phase composition of the zirconia, with relevant consequences on both the availability and stability of the copper phase, and the precise tuning of the acid-base properties that is still quite elusive. Moreover, under reaction conditions, zirconia-base materials modify and copper aggregation and loss and/or oxidation state changing make the stability of such systems the first issue that still need to be studied. Authors discussed some innovative potential uses, such as the transformation of biomass-derived platform molecules to high added-value products, showing catalytic routes from lignocelluloses stream based on zirconia systems still unexplored.

The redox and acid-base properties of zirconium oxide were also exploited by Tan et al. for isobutanol synthesis from syngas [3]. Authors investigated the effect of preparation methods on amorphous $\mathrm{ZrO}_{2}$-based catalysts, by exploiting different co-precipitation/reflux digestion methods 
with ethylenediamine and ammonia as precipitant, and copper and potassium as promoters added via impregnation. A different distribution of alcohols was observed on different $\mathrm{ZrO}_{2}$ based catalysts promoted with the same content of $\mathrm{Cu}$ and $\mathrm{K}$, even if both were characterized by an amorphous phase. Characterization results indicated that the A-KCZ catalyst (ammonia as precipitant) supplied more active isolated hydroxyls for anchoring and dispersing Cu compared with E-KCZ (ethylenediamine as precipitant). Specifically, in situ DRIFT measurements allowed investigations of the adsorption and activation of syngas molecules on catalyst surface and thus the study of hydroxyl groups and $\mathrm{C} 1$ intermediates. The formation of bicarbonate species on the $\mathrm{A}-\mathrm{KCZ}$ catalyst surface resulted to be as determinant $\mathrm{C} 1$ species for isobutanol formation, thanks to its long residence time, which allows further carbon chain growth.

The need to cut down the greenhouse-gas emissions is a great, pressing global scientific concern on novel catalytic technologies allowing an effective conversion and recycle of carbon dioxide [4]. In particular, using $\mathrm{CO}_{2}$ in place of $\mathrm{CO}$ for methanol synthesis would represent a decisive technological breakthrough, with a remarkable improvement of the overall process economics [5]. The $\mathrm{CO}_{2}$ conversion to methanol looks particularly attractive due to its extensive use for synthesizing liquid fuels such as hydrocarbons or dimethylether (DME), alternative to oil-derived ones and several bulk chemicals (formaldehyde, MTBE, acetic acid, etc.). Nevertheless, the potential use of methanol and derivatives (DME) as fuels for the automotive sector leads to forecast an impressive growth in methanol demand. DME is a biodegradable and environmentally friendly compound which could be used as an alternative to conventional fossil fuels, thanks to its positive profile of combustion, high cetane number and reduced combustion noise during engine warm-up [6]. Conventionally, DME is produced through a two-step process, according to which methanol is first synthesized from syngas and then DME is produced from the dehydration of methanol $[7,8]$ or in a single-step (direct) process $[9,10]$. In this Special Issue, a papers deals with the production of methanol, and two deal with the dehydration step to DME synthesis.

First, Bonura et al. investigated the activity-selectivity pattern of $\mathrm{Cu}_{\mathrm{x}} \mathrm{Zn}_{\mathrm{y}} \mathrm{Al}_{\mathrm{z}}$ catalysts, obtained from hydrotalcite method, in the $\mathrm{CO}_{2}$ hydrogenation to methanol, by evaluating the textural, structural and surface factors affecting catalytic functionality [11]. Characterization of solid systems shows a very homogeneous distribution of metals per unit area among the oxide species, able to ensure a suitable activation of $\mathrm{H}_{2}$ and $\mathrm{CO}_{2}$ reactants for a superior methanol production. The concentration of $\mathrm{Zn}$ controls the surface properties and, in particular, the reducibility of the systems, as well as the stabilization of $\mathrm{Cu}^{\delta+}$ sites at the metal/oxides interface, while a balanced "mix" of $\mathrm{Cu}^{0}, \mathrm{Cu}^{\delta+}$ and strong base sites positively affects the rate of methanol formation upon a favorable adsorption/activation of $\mathrm{H}_{2}$ and $\mathrm{CO}_{2}$. Textural and surface effects induced by the zinc concentration thus conferred a very interesting catalyst performance, with a methanol space time yield (STY) higher than that of commercial systems operated under the same experimental conditions.

Then, Migliori et al. studied the DME production reaction by evaluating the catalytic performance of hybrid metal/zeolite catalysts (CuZnZr/FER or MFI) in the dehydration step of methanol to DME [12]. Hybrid systems were prepared by using gel oxalate co-precipitation, which involves the co-precipitation of metals on the acid catalyst, previously dissolved in a solution with oxalic acid. The metal and acid sites' interaction shows a key role affecting the catalytic performance. Authors evaluated the deactivation of the solid systems, attributing the decrease in DME selectivity to the cooperation of metal and acid sites in the production of different compounds, such as methyl formate and dimethoxy methane, above all, on catalysts prepared by using ethanol as co-precipitation medium. The deactivation of the zeolite could be due to the migration of the atoms of $\mathrm{Cu}^{2+}$ and $\mathrm{Zn}^{2+}$ on the acidic sites and in the pores of the latter, in synergy with the possible sintering of metal particles, promoted by the water produced by the dehydration of methanol to DME. Thus, some parallel pathways are dependent on the zeolite structure and on the type of co-precipitation medium used during the synthesis. The results highlighted the existence of a potential shape selectivity of hybrid systems based on FER with respect to 
secondary products, but, at the same time, the presence of a relationship between the co-precipitation medium and the process selectivity toward dimethyl ether.

Recently, the catalytic performance of heteropolyacids (HPAs) in methanol conversion to DME reaction has been an object of study, with good results in terms of high reaction rate at relatively low reaction temperature $[13,14]$. On this account, Meng et al. developed a series of $\mathrm{Cu} / \mathrm{Fe}$-based Keggin-structure heteropolyacid salt catalysts, synthesized by a simple replacement reaction. The substitution with $\mathrm{Cu}^{2+}$ and $\mathrm{Fe}^{3+}$ ions allowed for a decrease in the acid density. In fact, two of the main drawbacks of HPAs catalysts are the low surface area and high acid strength, causing strong interaction between $\mathrm{H}_{2} \mathrm{O}$ and the acid sited of the HPA [14]. A $100 \%$ DME selectivity at $175-225^{\circ} \mathrm{C}$ was obtained and a long lifetime for methanol to DME reaction at $200^{\circ} \mathrm{C}$.

$\mathrm{CO}$ is the main product of the imperfect combustion of carbon and compounds containing carbon, and its high level in the atmosphere represents a serious health and environmental problem. Thus, many techniques were used to reduce its concentration, such as the catalytic oxidation of $\mathrm{CO}$ which proves to be one of the most effective techniques for removing this pollutant $[15,16]$. As regards $\mathrm{NOx}$, power plants, industrial boilers and motor-vehicle engine discharge $\mathrm{NO}_{x}$ via fossil fuels combustion inevitably [17]. They are very harmful for the ecosystem and humanity, too, contributing to photochemical smog, acid rain, ozone depletion and greenhouse effect. NO oxidation technology is considered an alternative for $\mathrm{NO}_{x}$ elimination, and it is also a critical step in SCR (selective catalytic reduction), LNT (lean $\mathrm{NO}_{x}$ trap) and NSR (NO $\mathrm{NO}_{x}$ storage-reduction) [18,19]. On this account, two papers deals with $\mathrm{CO}$ or $\mathrm{NO}$ oxidation techniques.

Tereshchenko et al. developed some supported palladium nanoparticles (PdNPs) on the modified nanoscale ceria support, exploiting the oxygen storage capacity of the ceria used as support, for the $\mathrm{CO}$ oxidation reaction at low temperature $\left(100 \% \mathrm{CO}\right.$ conversion at $\left.50^{\circ} \mathrm{C}\right)$ [20]. Specifically, authors treated ceria by surface modifiers, in order to increase the number of nucleation centers for palladium to form $\mathrm{Pd} /$ ceria nanoparticles. Conventional characterization techniques (TEM and XRDS) did not allow for the determining small palladium clusters, due to the low Z-contrast and small size of noble metal particles. A careful analysis of $\mathrm{CO}$ adsorption/desorption used as probe molecule and was carried out by DRIFTS measurements, providing unambiguous evidence for the Pd nanoparticles' formation, allowing the researchers to study the size and the morphology of both NPs and the ceria support. Solid characterization was then supported by XANES (X-ray absorption near edge structure analysis) measurements and $\mathrm{CO}$ chemisorption analysis.

The paper by Lin, Wang et al. deals with metal-oxide catalysts and their application for NO oxidation to $\mathrm{NO}_{2}$ [21]. Specifically, $\mathrm{MnOx}-\mathrm{CeO}_{2}$ composites catalysts were synthesized by ammonium carbonate co-precipitation method with $\mathrm{Sn}, \mathrm{Fe}, \mathrm{Co}, \mathrm{Cr}$ or $\mathrm{Cu}$. XRD, XPS, BET and $\mathrm{H}_{2}$-TPR were used to investigate the catalyst activity, and in situ DRIFTS measurements were conducted to investigate the surface species formation during $\mathrm{NO}$ oxidation and $\mathrm{SO}_{2}$ poisoning process. For $\mathrm{SO}_{2}$ poisoning, Fe addition into an MnCe catalyst could protect $\mathrm{Mn}$ and $\mathrm{Ce}$ metal oxides from being reduced. By DRIFTS investigations, the decomposition of surface nitrates at $\mathrm{SO}_{2}$ presence gave evidence to the decreasing $\mathrm{NO}$ conversion efficiency. Some nitrate species remained undestroyed on the MnCeFe catalyst surface after $\mathrm{SO}_{2}$ poisoning, due to its better $\mathrm{SO}_{2}$ tolerance.

At last, an interesting application of a low-cost material such as palm shell char as a catalyst for the catalytic steam reforming of tar after the sorption enhanced gasification process is reported by Chen et al. [22]. This study is particularly interesting, considering the increase in palm shell waste due to the high production of palm oil, which has doubled in the past two decades. Different from $\mathrm{CaO}$, it showed relatively low selectivity to benzene, and toluene and naphthalene are mainly decomposed to light components, generating extra syngas formation. It was also found that potassium and iron-loaded palm shell chars exhibited much better catalytic activity than palm shell char, while the parallel reaction of gasification of K-loaded palm shell char influenced the conversion with its drastic mass loss. 
Finally, I would like to express my sincerest thanks to all the authors for their valuable contributions and the editorial team of Catalysts for their kind support, without which the publication of this Special Issue would not have been possible.

\section{References}

1. Millar, G.J.; Rochester, C.H. An in situ high pressure FT-IR study of $\mathrm{CO}_{2} / \mathrm{H}_{2}$ interaction with model $\mathrm{ZnO} / \mathrm{SiO}_{2}$, $\mathrm{Cu} / \mathrm{SiO}_{2}$ and $\mathrm{Cu} / \mathrm{ZnO} / \mathrm{SiO}_{2}$ methanol synthesis catalysts. Catal. Lett. 1992, 14, 289-295. [CrossRef]

2. Scotti, N.; Bossola, F.; Zaccheria, F.; Ravasio, N. Copper-Zirconia catalysts: Powerful multifunctional catalytic tools to approach sustainable processes. Catalysts 2020, 10, 168. [CrossRef]

3. Wu, Y.; Tan, L.; Zhang, T.; Xie, H.; Yang, G.; Tsubaki, N.; Chen, J. Effect of preparation method on $\mathrm{ZrO}_{2}$-based catalysts performance for isobutanol synthesis from syngas. Catalysts 2019, 9, 752. [CrossRef]

4. Bonura, G.; Arena, F.; Mezzatesta, G.; Cannilla, C.; Spadaro, L.; Frusteri, F. Role of the ceria promoter and carrier on the functionality of $\mathrm{Cu}$-based catalysts in the $\mathrm{CO}_{2}$-to-methanol hydrogenation reaction. Catal. Today 2011, 171, 251-256. [CrossRef]

5. Peters, M.; Köhler, B.; Kuckshinrichs, W.; Leitner, W.; Markewitz, P.; Müller, T.E. Chemical technologies for exploiting and recycling carbon dioxide into the value chain. ChemSusChem 2011, 4, 1216-1240. [CrossRef] [PubMed]

6. Bonura, G.; Migliori, M.; Frusteri, L.; Cannilla, C.; Catizzone, E.; Giordano, G.; Frusteri, F. Acidity control of zeolite functionality on activity and stability of hybrid catalysts during DME production via $\mathrm{CO}_{2}$ hydrogenation. J. $\mathrm{CO}_{2}$ Util. 2018, 24, 398-406. [CrossRef]

7. Zhu, Y.; Wang, S.; Ge, X.; Liu, Q.; Luo, Z.; Cen, K. Experimental study of improved two step synthesis for DME production. Fuel Process. Technol. 2010, 91, 424-429. [CrossRef]

8. Bae, J.W.; Kang, S.H.; Lee, Y.J.; Jun, K.W. Effect of precipitants during the preparation of Cu- $\mathrm{ZnO}-\mathrm{Al}_{2} \mathrm{O}_{3} / \mathrm{Zr}$-ferrierite catalyst on the DME synthesis from syngas. J. Ind. Eng. Chem. 2009, 15, 566-572. [CrossRef]

9. Frusteri, F.; Cordaro, M.; Cannilla, C.; Bonura, G. Multifunctionality of $\mathrm{Cu}-\mathrm{ZnO}-\mathrm{ZrO}_{2} / \mathrm{H}_{-}-\mathrm{ZSM}_{5}$ catalysts for the one-step $\mathrm{CO}_{2}$-to-DME hydrogenation reaction. Appl. Catal. B 2015, 162, 57-65. [CrossRef]

10. Bonura, G.; Cannilla, C.; Frusteri, L.; Mezzapica, A.; Frusteri, F. DME production by $\mathrm{CO}_{2}$ hydrogenation: Key factors affecting the behaviour of CuZnZr/ferrierite catalysts. Catal. Today 2017, 281, 337-344. [CrossRef]

11. Frusteri, L.; Cannilla, C.; Todaro, S.; Frusteri, F.; Bonura, G. Tailoring of Hydrotalcite-derived Cu-based catalysts for $\mathrm{CO}_{2}$ hydrogenation to methanol. Catalysts 2019, 9, 1058. [CrossRef]

12. Migliori, M.; Condello, A.; Dalena, F.; Catizzone, E.; Giordano, G. CuZnZr-Zeolite hybrid grains for DME synthesis: New evidence on the role of metal-acidic features on the methanol conversion step. Catalysts 2020, 10, 671. [CrossRef]

13. Lertjiamratn, K.; Praserthdam, P.; Arai, M.; Panpranot, J. Modification of acid properties and catalytic properties of $\mathrm{AlPO}_{4}$ by hydrothermal pretreatment for methanol dehydration to dimethyl ether. Appl. Catal. A Gen. 2010, 378, 119-123. [CrossRef]

14. Ladera, R.M.; Ojeda, M.; Fierro, J.L.G.; Rojas, S. $\mathrm{TiO}_{2}$-supported heteropoly acid catalysts for dehydration of methanol to dimethyl ether: Relevance of dispersion and support interaction. Catal. Sci. Technol. 2015, 5, 484-491. [CrossRef]

15. Yoshida, T.; Murayama, T.; Sakaguchi, N.; Okumura, M.; Ishida, T.; Haruta, M. Carbon monoxide oxidation by polyoxometalate-supported gold nanoparticulate catalysts: Activity, stability, and temperature-dependent activation properties. Angew. Chem. 2018, 130, 1539-1543. [CrossRef]

16. Kaneti, Y.V.; Tanaka, S.; Jikihara, Y.; Nakayama, T.; Bando, Y.; Haruta, M.; Hossain, S.A.; Golberg, D.; Yamauchi, Y. Room temperature carbon monoxide oxidation based on two-dimensional gold-loaded mesoporous iron oxide nanoflakes. Chem. Commun. 2018, 54, 8514-8517. [CrossRef]

17. Zhang, Y.; You, R.; Liu, D.; Liu, C.; Li, X.; Tian, Y.; Jiang, Z.; Zhang, S.; Huang, Y.; Zha, Y. Carbonates-based noble metal-free lean $\mathrm{NOx}$ trap catalysts $\mathrm{MO}_{\mathrm{x}}-\mathrm{K}_{2} \mathrm{CO}_{3} / \mathrm{K}_{2} \mathrm{Ti}_{8} \mathrm{O}_{17}(\mathrm{M}=\mathrm{Ce}, \mathrm{Fe}, \mathrm{Cu}, \mathrm{Co})$ with superior catalytic performance. Appl. Surf. Sci. 2015, 357, 2260-2276. [CrossRef]

18. Zhang, S.; Li, H.; Zhong, Q. Promotional effect of F-doped $\mathrm{V}_{2} \mathrm{O}_{5}-\mathrm{WO}_{3} / \mathrm{TiO}_{2}$ catalyst for $\mathrm{NH}_{3}-\mathrm{SCR}$ of $\mathrm{NO}$ at low-temperature. Appl. Catal. A Gen. 2012, 435, 156-162. [CrossRef] 
19. Scholz, C.; Gangwal, V.; De Croon, M.; Schouten, J. Influence of $\mathrm{CO}_{2}$ and $\mathrm{H}_{2} \mathrm{O}$ on NOx storage and reduction on a Pt-Ba $/ \gamma-\mathrm{Al}_{2} \mathrm{O}_{3}$ catalyst. Appl. Catal. B Environ. 2007, 71, 143-150. [CrossRef]

20. Tereshchenko, A.A.; Polyakov, V.A.; Guda, A.A.; Lastovina, T.; Pimonova, Y.; Bulgakov, A.; Tarasov, A.L.; Kustov, L.M.; Butova, V.V.; Trigub, A.L.; et al. Ultra-Small Pd nanoparticles on ceria as an advanced catalyst for CO oxidation. Catalysts 2019, 9, 385. [CrossRef]

21. Shao, J.; Lin, F.; Li, Y.; Tang, H.; Wang, Z.; Liu, P.; Chen, G. Co-precipitation synthesized $\mathrm{MnO}_{\mathrm{x}}-\mathrm{CeO}_{2}$ mixed oxides for $\mathrm{NO}$ oxidation and enhanced resistance to low concentration of $\mathrm{SO}_{2}$ by metal addition. Catalysts 2019, 9, 519. [CrossRef]

22. Chen, Y.-H.; Schmid, M.; Chang, C.-C.; Chang, C.-Y.; Scheffknecht, G. Lab-scale investigation of palm shell char as tar reforming catalyst. Catalysts 2020, 10, 476. [CrossRef]

(C) 2020 by the author. Licensee MDPI, Basel, Switzerland. This article is an open access article distributed under the terms and conditions of the Creative Commons Attribution (CC BY) license (http://creativecommons.org/licenses/by/4.0/). 